\section{JURNAL EKONOMI EFEKTIF}

ISSN : $2622-8882$, E-ISSN : 2622-9935

Jurnal Ekonomi Efektif, Vol. 3, No. 3, April 2021

@Prodi Manajemen Fakultas Ekonomi Universitas

Pamulang

\title{
PENGARUH PROMOSI JABATAN TERHADAP PRESTASI KERJA KARYAWAN PADA PT. AJB BUMIPUTERA SYARIAH CABANG PONDOK GEDE
}

\author{
Lily Setyawati Kristianti \\ Universitas Pamulang, Tangerang Selatan, Banten, Indonesia \\ dosen02521@unpam.ac.id
}

Manuskrip: Feb-2021 Ditinjau: Mar-2021; Diterima: Mar-2021; Online: Apr-2021; Diterbitkan: Apr-2021

\begin{abstract}
ABSTRAK
Penelitian ini bertujuan untuk mengetahui pengaruh Promosi Jabatan terhadap Prestasi Kerja Karyawan pada PT. AJB Bumiputera Syariah Cabang Pondok Gede. Metode yang digunakan adalah explanatory research dengan sampel sebanyak 62 responden. Teknik analisis menggunakan analisis statistik dengan pengujian regresi, korelasi, determinasi dan uji hipotesis. Hasil penelitian ini variabel Promosi Jabatan diperoleh nilai rata-rata skor sebesar 3,737 dengan kriteria baik. Variabel Prestasi Kerja Karyawan diperoleh nilai rata-rata skor sebesar 3,781 dengan kriteria baik. Promosi Jabatan berpengaruh positif dan signifikan terhadap Prestasi Kerja Karyawan dengan nilai persamaan regresi $\mathrm{Y}=11,671+0,699 \mathrm{X}$, dan nilai koefisien korelasi 0,793 atau memiliki tingkat hubungan yang kuat dengan nilai determinasi 62,8\%. Uji hipotesis diperoleh signifikansi $0,000<0,05$.
\end{abstract}

\section{Kata Kunci: Promosi Jabatan, Prestasi Kerja Karyawan.}

\section{ABSTRACT}

This study aims to determine the effect of Job Promotion on Employee Performance at PT. AJB Bumiputera Syariah Pondok Gede Branch. The method used is explanatory research with a sample of 62 respondents. The analysis technique uses statistical analysis with regression testing, correlation, determination and hypothesis testing. The results of this research variable Job Promotion obtained an average score of 3,737 with good criteria. Employee Performance Variable obtained an average score of 3,781 with good criteria. Job Promotion has a positive and significant effect on Employee Performance with a regression equation value of $Y=11.671+0.699 X$, and a correlation coefficient value of 0.793 or has a strong level of relationship with a determination value of 62.8\%. Hypothesis testing obtained a significance of $0.000<0.05$.

Keywords: Job Promotion, Employee Performance. 


\section{PENDAHULUAN}

\section{A. Latar Belakang Masalah}

Manajemen adalah ilmu seni mengatur proses pemanfaatan sumber daya manusia dan sumber daya lainnya secara efektif dan efisien untuk mencapai suatu tujuan tertentu.

Manajemen menurut Terry dan Leslie W. Rue (2016) adalah suatu proses atau kerangka kerja yang melibatkan bimbingan atau pengarahan suatu kelompok orang kearah tujuan - tujuan organisasional atau maksud - maksud yang nyata. Manajemen bergerak dalam suatu organisasi, dimana manajemen tersebut mempunyai peranan yang sangat penting dalam mencapai tujuan yg nyata.

Jadi kesimpulannya manajemen adalah imu dan seni yang mengatur proses pemanfaatan sumber daya manusia agar pekerjaan dapat diselesaikan secara efektif dan efisien melalui orang lain untuk mencapai tujuan yang ditetapkan oleh organisasi. Dalam rangka menghadapi persaingan dunia usaha yang semakin kompetitif, perusahaan dituntut untuk dapat mengoptimalkan semua sumber daya yang dimiliki. Tidak sedikit jumlahnya para ilmuwan yang menganggap faktor-faktor produksi tersebut sama pentingnya (yang satu tidak lebih rendah dari yang lain). Di lain pihak, tidak sedikit pengusaha yang hanya menganggap penting faktor produksi modal. Walaupun sumber daya tersebut penting bagi organisasi, faktor yang menunjukkan keunggulan kompetitif potensial perusahaan adalah sumber daya manusia.

Tanpa adanya sumber daya manusia yang menggerakkan faktor-faktor produksi, sumber-sumber yang dimiliki tidak akan dapat produktif. Sumber daya manusia membuat sumber daya organisasi lainnya berjalan.

Mengingat begitu vitalnya peranan sumber daya manusia dalam suatu perusahaan, sudah sepatutnya jika suatu perusahaan memperhatikan aspek- aspek kerja yang berkaitan dengan sumber daya manusia. Hal tersebut diharapkan karyawan yang memiliki motivasi kerja yang kuat merupakan keunggulan kompetitif suatu perusahaan. Pada dasarnya, perusahaan bukan saja mengharapkan karyawan yang memiliki tingkat intelejensi tinggi, tetapi yang terpenting mereka mau bekerja giat dan berkeinginan untuk mencapai hasil kerja yang optimal. Kemampuan, kecakapan, dan keterampilan karyawan tidak ada artinya bagi perusahaan tanpa adanya kerja keras.

Pengembangan sumber daya manusia merupakan cara agar dapat mempertahankan eksitensi kerja semua komponen organisasi. Sebuah organisasi harus mampu mengoptimalkan kemampuan sumber daya manusia yang dimilikinya agar pencapaian sasaran dapat terlaksana, namun hal tersebut tidaklah sederhana perlu pemahaman yang baik tentang organisasi terpakai sesuai kebutuhan, tentunya pimpinan perusahaan perlu pemahaman yang baik tentang organisasi, perlu ada strategi pengembangan yang matang agar sumber daya manusia yang dimiliki sebuah organisasi terpakai sesuai kebutuhan, tentunya pimpinan perusahaan perlu memotivasi karyawannya yaitu dengan promosi jabatan.

Masalah yang timbul adalah bahwa kebutuhan masing-masing orang berbeda satu dengan yang lain. Maka perusahaan haruslah menjadi suatu lembaga yang menyediakan kesempatan dalam pemenuhan kebutuhan bagi para pekerjanya.

Seseorang cenderung bekerja dengan penuh semangat apabila promosi jabatan dapat diperolehnya dari pekerjaannya dan promosi jabatan kerja karyawan merupakan kunci pendorong moral, dan prestasi kerja karyawan dalam mendukung terwujudnya tujuan perusahaan (Hasibuan, 2011:203).

Menurut Sondang P. Siagian (2012:169) promosi jabatan adalah pemindahan karyawan dari satu jabatan atau tempat kepada jabatan atau tempat lain yang lebih tinggi disertai tugas, tanggung jawab dan wewenang yang lebih tinggi dari jabatan yang 
diduduki sebelumnya.

Promosi jabatan dilaksanakan untuk mengoptimalkan sumber daya manusia yang dimiliki organisasi, selain itu promosi jabatan bertujuan untuk meregenerasi sumber daya manusia dalam organisasi demi kelangsungan organisasi. Prestasi kerja karyawan merupakan tolak ukur utama dalam pengembangan sumber daya manusia.

Menurut Hasibuan (2010:105) prestasi kerja adalah suatu hasil kerja yang dicapai seseorang dalam pelaksanaan tugas - tugas yang dibebankan kepadanya yang didasarkan pada kecakapan dan ketepatan waktu. Sedangkan menurut Mangkunegara (2011:67) prestasi kerja adalah hasil kerja secara kualitas dan kuantitas yang dicapai oleh seseorang karyawan dalam melaksanakan tugasnya sesuai dengan tanggung jawab yang diberikan kepadanya.

PT. AJB Bumiputera Syariah 1912 Syariah merupakan bagian atau divisi dari perusahaan asuransi jiwa tertua di Indonesia. PT AJB Bumiputera 1912 Syariah sendiri dibentuk tahun 2002 atas dasar fatwa Dewan Syariah Nasional No. 21/DSN MUI/X/2001 tanggal 17 Oktober 2001, dan keputusan Menteri Keuangan RI No.Kep268/KM-6/2002 tanggal 7 November 2002. Masalah sumber daya manusia yang menyangkut prestasi kerja juga terjadi di PT. AJB Bumiputera Syariah 1912 Syariah. Dalam hal ini PT. AJB Bumiputera Syariah 1912 Syariah membagi karyawan atas pegawai dinas dalam dan pegawai dinas luar (agen).

Para pegawai sangat membutuhkan prestasi kerja yang tinggi, karena dengan memiliki prestasi kerja yang tinggi, tujuan yang realitas, rencana kerja yang menyeluruh akan berjalan sesuai dengan yang diharapkan. Hal tersebut akan berdampak pada target premi yang ditentukan perusahaan dapat tercapai. Untuk mencapai target premi, ada dua kiat utama yang dijalankan. Pertama mengedapankan kepentingan dinas di atas kepentingan pribadi. Kedua, mengadakan pertemuan rutin untuk memberikan motivasi, evaluasi dan menambah skill penjualan yang baik terutama untuk mengahadapi prospek (calon nasabah/pemegang polis) serta mensosialisasikan nota-nota dinas yang berhubungan dengan produk asuransi ataupun teknis pelaksanaannya.

Dalam hal ini peran agen PT. AJB Bumiputera Syariah 1912 Syariah sangat vital. Pada umumnya para agen asuransi jiwa belum memiliki kualifikasi seperti yang diharapkan, ditandai dengan tingginya agen yang keluar. Dengan adanya masalah tersebut, tujuan pemberdayaan agen guna meningkatkan pendapatan premi dan pertumbuhan industri asuransi jiwa, bisa saja tidak tercapai secara optimal.

Hal tersebut berkaitan dengan promosi jabatan dan prestasi kerja. Artinya, agen yang tidak termotivasi biasanya memiliki prestasi kerja yang kurang bagus dan kurang menikmati pekerjaan sehingga memutuskan berhenti atau malah diberhentikan. Hal tersebut menandakan adanya prestasi kerja agen PT. AJB Bumiputera Syariah 1912 Syariah antara kondisi kerja dengan yang diharapkan. Hal lain yang menyebabkan prestasi kerja yang belum tercapai adalah rendahnya intensitas dalam melakukan pertemuan rutin untuk memberikan motivasi, evaluasi dan menambah skill penjualan yang baik. Dalam satu bulan pertemuan rutin dilakukan hanya satu kali. Hal tersebut menyebabkan rendahnya persepsi agen asuransi PT. AJB Bumiputera Syariah 1912 Syariah terhadap karakteristik pekerjaan itu sendiri.

Pekerjaan agen asuransi jiwa memiliki beberapa karakteristik. Pekerjaan ini sangat menuntut kemampuan menjual dari agen, karena menjual produk asuransi, berbeda jauh dan sulit dibanding menjual barang yang wujudnya dapat dilihat langsung konsumen. Oleh karena itu, setiap agen harus benar - benar bisa mengerti produk yang dijualnya.

Promosi agen pada PT. AJB Bumiputera Syariah 1912 Syariah dilaksanakan apabila dalam satu sampai dua tahun agen dapat mencapai target premi. Kenyataan di 
lapangan, dari tahun 2014-2015 terjadi penurunan jumlah agen yang dapat mencapai target. Target premi yang menurun agen terlalu besar menyebabkan tidak tercapainya target sehingga mengakibatkan promosi sangat sulit terjadi pada para karyawan (agen).

Tabel 1 Pencapaian Target Karyawan

\begin{tabular}{|c|c|c|c|c|c|}
\hline \multirow{2}{*}{ Tahun } & \multirow{2}{*}{$\begin{array}{c}\text { Jumlah } \\
\text { Karyawan }\end{array}$} & \multicolumn{2}{|c|}{ Mencapai Target } & \multicolumn{2}{c|}{$\begin{array}{c}\text { Tidak Mencapai } \\
\text { Target }\end{array}$} \\
\cline { 3 - 6 } & & Orang & $\%$ & Orang & $\%$ \\
\hline 2016 & 65 & 52 & $80,0 \%$ & 13 & $20,0 \%$ \\
\hline 2017 & 60 & 51 & $85,0 \%$ & 9 & $15,0 \%$ \\
\hline 2018 & 62 & 48 & $77,4 \%$ & 14 & $22,6 \%$ \\
\hline 2019 & 62 & 43 & $69,4 \%$ & 19 & $30,6 \%$ \\
\hline Rata-rata & & 48,5 & $77,9 \%$ & 13,8 & $22,1 \%$ \\
\hline
\end{tabular}

Berdasarkan pada data tabel di atas, menunjukkan bahwa dari jumlah karyawan yang ada, jumlah yang mencapai target sangat minim dan yang belum mencapai target justru semakin banyak. Hal ini harus segera dilakukan pembenahan mengingat kinerja karyawan sangat penting dalam menunjang tercapainya tujuan organisasi.

Masalah promosi jabatan terhadap prestasi kerja memiliki peranan penting dalam rangka memenuhi kebutuhan kepentingan perusahaan akan karyawannya untuk benarbenar mampu dan menguasai jenis-jenis pekerjaan baru tersebut.

Berdasarkan uraian tersebut diatas, jelaslah bahwa pelaksanaan promosi jabatan berhubungan erat dengan prestasi kerja karyawan. Untuk itu penulis sangat tertarik untuk membahas masalah tersebut dalam sebuah penelitianyang berjudul "Pengaruh Promosi jabatan terhadap prestasi kerja karyawan. (Studi Kasus Pada PT. AJB Bumiputera Syariah 1912 Syariah Cabang Pondok Gede).

\section{B. Rumusan Masalah}

1. Bagaimana Promosi Jabatan pada PT. AJB Bumiputera Syariah Cabang Pondok Gede ?.

2. Bagaimana Prestasi Kerja Karyawan pada PT. AJB Bumiputera Syariah Cabang Pondok Gede?.

3. Adakah pengaruh antara Promosi Jabatan terhadap Prestasi Kerja Karyawan pada PT. AJB Bumiputera Syariah Cabang Pondok Gede?.

\section{Tujuan Penelitian}

1. Untuk mengetahui kondisi Promosi Jabatan pada PT. AJB Bumiputera Syariah Cabang Pondok Gede.

2. Untuk mengetahui kondisi Prestasi Kerja Karyawan pada PT. AJB Bumiputera Syariah Cabang Pondok Gede.

3. Untuk mengetahui pengaruh antara Promosi Jabatan terhadap Prestasi Kerja Karyawan pada PT. AJB Bumiputera Syariah Cabang Pondok Gede.

\section{METODE PENELITIAN}

\section{Populasi}

Populasi dalam penelitian ini berjumlah 62 responden PT. AJB Bumiputera Syariah Cabang Pondok Gede

\section{Sampel}

Teknik pengambilan sampling dalam penelitian ini adalah sampel jenuh, dimana semua anggota populasi dijadikan sebagai sampel. Dengan demikian sampel dalam penelitian ini sampel yang digunakan berjumlah 62 responden. 


\section{Jenis Penelitian}

Jenis penelitian yang dipakai adalah asosiatif, dimana tujuannya adalah untuk mengetahui atau mencari keterhubungan antara variabel independen terhadap variabel dependennya.

\section{Metode Analisis Data}

Dalam menganalisis data digunakan uji validitas, uji reliabilitas, analisis regresi linier sederhana, analisis koefisien korelasi, analisis koefisien determinasi dan pengujian hipotesis.

\section{HASIL PENELITIAN DAN PEMBAHASAN}

\section{Analisis Deskriptif}

Pada pengujian ini digunakan untuk mengetahui skor minimum dan maksimum skor tertinggi, ratting score dan standar deviasi dari masing-masing variabel. Adapun hasilnya sebagai berikut:

Tabel 2. Hasil Analisis Descriptive Statistics

Descriptive Statistics

\begin{tabular}{lr|r|r|r|r} 
& N & \multicolumn{1}{|c|}{ Minimum } & Maximum & \multicolumn{1}{c|}{ Mean } & \multicolumn{1}{c}{ Std. Deviation } \\
\hline Promosi Jabatan (X) & 80 & 28 & 44 & 34.00 & 4.016 \\
\hline Prestasi Kerja Karyawan (Y) & 80 & 29 & 49 & 38.11 & 4.183 \\
\hline Valid N (listwise) & 80 & & & &
\end{tabular}

Promosi Jabatan diperoleh varians minimum sebesar 29 dan varians maximum 49 dengan ratting score sebesar 3,737 dengan standar deviasi 4,688. Skor ini termasuk pada rentang sakala 3,40 - 4,19 dengan kriteria baik atau setuju.

Prestasi Kerja Karyawan diperoleh varians minimum sebesar 29 dan varians maximum 48 dengan ratting score sebesar 3,781 dengan standar deviasi 4,136. Skor ini termasuk pada rentang sakala 3,40 - 4,19 dengan kriteria baik atau setuju.

\section{Analisis Verifikatif.}

Pada analisis ini dimaksudkan untuk mengetahui pengaruh variabel independen terhadap variabel dependen. Adapun hasil pengujian sebagai berikut:

\section{a. Analisis Regresi Linier Sederhana}

Uji regresi ini dimaksudkan untuk mengetahui perubahan variabel dependen jika variabel independen mengalami perubahan. Adapun hasil pengujiannya sebagai berikut:

Tabel 3. Hasil Pengujian Regresi Linier Sederhana

\section{Coefficients $^{\mathrm{a}}$}

\begin{tabular}{|c|c|c|c|c|c|}
\hline \multirow[b]{2}{*}{ Model } & \multicolumn{2}{|c|}{ Unstandardized Coefficients } & $\begin{array}{l}\text { Standardized } \\
\text { Coefficients }\end{array}$ & $\mathrm{t}$ & Sig. \\
\hline & $\mathrm{B}$ & Std. Error & Beta & & \\
\hline (Constant) & 11.671 & 2.616 & & 4.462 & .000 \\
\hline Promosi Jabatan (X) & 699 & .069 & .793 & 10.068 & .000 \\
\hline
\end{tabular}

Berdasarkan hasil pengujian pada tabel di atas, diperoleh persamaan regresi $\mathrm{Y}$

$=11,671+0,699 X$. Dari persamaan tersebut dijelaskan sebagai berikut:

1) Konstanta sebesar 11,671 diartikan jika Promosi Jabatan tidak ada, maka telah terdapat nilai Prestasi Kerja Karyawan sebesar 11,671 point.

2) Koefisien regresi Promosi Jabatan sebesar 0,699, angka ini positif artinya setiap ada peningkatan Promosi Jabatan sebesar 0,699 point maka Prestasi Kerja Karyawan juga akan mengalami peningkatan sebesar 0,699 point. 


\section{b. Analisis Koefisien Korelasi}

Analisis koefisien korelasi dimaksudkan untuk mengetahui tingkat kekuatan hubungan dari variabel independen terhadap variabel dependen. Adapun hasil pengujian sebagai berikut:

Tabel 4. Hasil Pengujian Koefisien Korelasi Promosi Jabatan Terhadap Prestasi

Kerja Karyawan.

\section{Correlations $^{\mathrm{b}}$}

\begin{tabular}{llr|r} 
& & & \multicolumn{2}{|c}{$\begin{array}{r}\text { Kinerja Karyawan } \\
\text { (Y) }\end{array}$} \\
\hline Promosi Jabatan (X) & Pearson Correlation & 1 & $.767^{* *}$ \\
\cline { 2 - 4 } & Sig. (2-tailed) & & .000 \\
\hline Prestasi Kerja Karyawan (Y) & Pearson Correlation & $.767^{* *}$ & 1 \\
\cline { 2 - 4 } & Sig. (2-tailed) & .000 & \\
\hline
\end{tabular}

Berdasarkan hasil pengujian diperoleh nilai korelasi sebesar 0,793 artinya

Promosi Jabatan memiliki hubungan yang kuat terhadap Prestasi Kerja Karyawan.

\section{c. Analisis Koefisien Determinasi}

Analisis koefisien determinasi dimaksudkan untuk mengetahui besarnya persentase pengaruh dari variabel independen terhadap variabel dependen. Adapun hasil pengujian sebagai berikut:

Tabel 5. Hasil Pengujian Koefisien Determinasi Promosi Jabatan Terhadap Prestasi

Kerja Karyawan.

Model Summary

\begin{tabular}{lr|r|r|r} 
Model & & \multicolumn{2}{c}{$\begin{array}{c}\text { Adjusted R } \\
\text { Square }\end{array}$} & $\begin{array}{c}\text { Std. Error of the } \\
\text { Estimate }\end{array}$ \\
\hline 1 & $\mathrm{R}$ & R Square & \multicolumn{1}{c}{ Squar } \\
\hline
\end{tabular}

a. Predictors: (Constant), Promosi Jabatan (X)

Berdasarkan hasil pengujian diperoleh nilai determinasi sebesar 0,628 artinya Promosi Jabatan memiliki kontribusi pengaruh sebesar 62,8\% terhadap Prestasi Kerja Karyawan, sedangkan sisanya sebesar 37,2\% dipengaruhi oleh faktor lain yang tidak dilakukan penelitian.

\section{d. Uji Hipotesis}

Pengujian hipotesis dengan uji $\mathrm{t}$ digunakan untuk mengetahui hipotesis mana yang diterima. Rumusan hipotesis: Terdapat pengaruh yang signifikan antara Promosi Jabatan terhadap Prestasi Kerja Karyawan.

Tabel 6. Hasil Uji Hipotesis Promosi Jabatan Terhadap Prestasi Kerja Karyawan.

\section{Coefficients $^{\mathrm{a}}$}

\begin{tabular}{|c|c|c|c|c|c|c|}
\hline \multirow{2}{*}{\multicolumn{2}{|c|}{ Model }} & \multicolumn{2}{|c|}{$\begin{array}{l}\text { Unstandardized } \\
\text { Coefficients }\end{array}$} & \multirow{2}{*}{$\begin{array}{c}\text { Standardized } \\
\text { Coefficients } \\
\text { Beta }\end{array}$} & \multirow[b]{2}{*}{$\mathrm{t}$} & \multirow[b]{2}{*}{ Sig. } \\
\hline & & $\mathrm{B}$ & Std. Error & & & \\
\hline \multirow[t]{2}{*}{1} & (Constant) & 11.671 & 2.616 & & 4.462 & .000 \\
\hline & Promosi Jabatan (X) & .699 & .069 & .793 & 10.068 & .000 \\
\hline
\end{tabular}

a. Dependent Variable: Prestasi Kerja Karyawan (Y)

Berdasarkan hasil pengujian pada tabel di atas, diperoleh nilai $\mathrm{t}$ hitung $>\mathrm{t}$ tabel atau $(10,068>2,000)$, dengan demikian hipotesis yang diajukan bahwa terdapat pengaruh yang signifikan atara Promosi Jabatan terhadap Prestasi Kerja Karyawan diterima. 


\section{PEMBAHASAN HASIL PENELITIAN}

\section{Kondisi Jawaban Responden Variabel Promosi Jabatan}

Berdasarkan jawaban responden, variabel Promosi Jabatan diperoleh ratting score sebesar 3,737 berada di rentang skala 3,40-4,19 dengan kriteria baik atau setuju.

\section{Kondisi Jawaban Responden Variabel Prestasi Kerja Karyawan}

Berdasarkan jawaban responden, variabel Prestasi Kerja Karyawan diperoleh ratting score sebesar 3,781 berada di rentang skala 3,40 - 4,19 dengan kriteria baik atau setuju.

\section{Pengaruh Promosi Jabatan Terhadap Prestasi Kerja Karyawan}

Promosi Jabatan berpengaruh signifikan terhadap Prestasi Kerja Karyawan dengan persamaan regresi $\mathrm{Y}=11,671+0,699 \mathrm{X}$, nilai korelasi sebesar 0,793 atau memiliki hubungan yang kuat dengan kontribusi pengaruh sebesar $62,8 \%$. Pengujian hipotesis diperoleh nilai t hitung $>\mathrm{t}$ tabel atau $(10,068>2,000)$. Dengan demikian hipotesis yang diajukan bahwa terdapat berpengaruh signifikan antara Promosi Jabatan terhadap Prestasi Kerja Karyawan diterima.

\section{PENUTUP}

\section{Kesimpulan}

a. Variabel Promosi Jabatan diperoleh ratting score sebesar 3,737 berada di rentang skala 3,40 - 4,19 dengan kriteria baik atau setuju.

b. Variabel Prestasi Kerja Karyawan diperoleh ratting score sebesar 3,781 berada di rentang skala 3,40 - 4,19 dengan kriteria baik atau setuju.

c. Promosi Jabatan berpengaruh signifikan terhadap Prestasi Kerja Karyawan dengan persamaan regresi $\mathrm{Y}=11,671+0,699 \mathrm{X}$, nilai korelasi sebesar 0,793 atau kuat dan kontribusi pengaruh sebesar $62,8 \%$ sedangkan sisanya sebesar $37,2 \%$ dipengaruhi faktor lain. Uji hipotesis diperoleh nilai thitung > t tabel atau $(10,068>2,000)$.

\section{Saran}

a. Dengan hasil penelitian, kejujuran karyawan mempengaruhi promosi jabatan dan perusahaan menetapkan promosi jabatan berdasarkan pengalaman.

b. Berdasarkan hasil penelitian, dengan kuantitas kerja karyawan dapat menyelesaikan pekerjaan lebih cepat dari waktu yang ditentukan, oleh karena itu karyawan konsisten dan tanggung jawab atas job description yang diberikan.

\section{DAFTAR PUSTAKA}

Affandi, A, et al (2020). Manajemen SDM Strategik. Serang. Bintang Visitama

Affandi, A., Sarwani, A. S., Erlangga, H., Siagian, A. O., Purwanto, A., Effendy, A. A., ... \& Wahyitno, C. D. M. (2020). Optimization of MSMEs Empowerment in Facing Competition in the Global Market during the COVID-19 Pandemic Time. Systematic Reviews in Pharmacy, 11(11), 1506-1515.

AM, E. N., Affandi, A., Udobong, A., \& Sarwani, S. (2020). Implementation of Human Resource Management in the Adaptation Period for New Habits. International Journal of Educational Administration, Management, and Leadership, 19-26.

Bacaal, Robert. 2010. "Ravitalisasi Sumber Daya Manusia dalam Era Perubahan". : Jakarta, Yayasan Universitas Indonesia.

Douglas, Mc Gregor, 2010, "The Human Side Of Enterprise”. : New York.

Fahmi, Irham. Pengantar Manajemen Sumber Daya Mnusia konsep dan kinerja. Penerbit: 
PT. Mitra Wacana Media, Jakarta, 2016

Flippo, Edwin B. 2012. "Manajemen Personalia Edisi Keenam, Jilid Dua". Jakarta : Erlangga.

George, Terry R. 2014. "Principles Of Management Edisi Tujuh". Jakarta : Erlangga.

Handoko, T. Hani, 2013. "Manajemen Personalia dan SDM", Edisi Kedua , PT BPFE, : Yogyakarta.

Hasibuan, Malayu. 2008. "Manajemen Sumber Daya Manusia”. Edisi Revisi cetakan keenam, jakarta PT. Bumi Aksara.

Hasibuan, Malayu. 2010. "Manajemen Sumber Daya Manusia”. Jakarta : PT Bumi Aksara.

Kristianti, L. S., Affandi, A., Nurjaya, N., Sunarsi, D., \& Rozi, A. (2021). Pengaruh Motivasi Dan Disiplin Kerja Terhadap Kinerja Pegawai Pada Dinas Pariwisata Purwakarta. Jurnal Ilmah PERKUSI, 1(1), 101-109.

Mangkunegara, AA. Anwar, Dr..Manajemen Sumber Daya Perusahaan, cetakan kesembilan. Penerbit: PT. Remaja Rusda Karya, Bandung, 2009

Mangkunegara, Anwar Prabu. 2011. "Manejemen Sumber Daya Mausia Perusahaan" . Bandung : PT Remaja Rosdakarya.

Mangkunegara, Anwar Prabu. 2013“Evaluasi Kinerja Sumber Daya Manusia”., Bandung : Refika Aditama.

Manullang. 2012, “Dasar-Dasar Manajemen”, Jakarta : PT. Ghalia Indonesia.

Nurjaya, N., Sobarna, A., Affandi, A., Erlangga, H., \& Sarwani, S. (2020). Edupreneurship management in shaping the nation's character. Jurnal Konseling dan Pendidikan, 8(3), 198-206.

Nurjaya, N., Sunarsi, D., Effendy, A. A., Teriyan, A., \& Gunartin, G. (2021). Pengaruh Etos Kerja Dan Disiplin Kerja Terhadap Kinerja Pegawai Pada Dinas Kehutanan Dan Perkebunan Kota Bogor. JENIUS (Jurnal Ilmiah Manajemen Sumber Daya Manusia), 4(2), 172-184.

Rivai, Vethzal \& Basri. 2010. "Performance Appraisal : Sistem yang tepat untuk Menilai Kinerja Karyawan dan Meningkatkan Daya Saing Perusahaan”. Jakarta : PT RajaGrafindo Persada.

S. Nitisemito, Alex, 2014. "Manajemen Personalia", Cetakan Kesembilan Edisi Ke Tiga, Jakarta : Ghalia.

Sareno, S. (2019). Pengaruh Kedisiplinan Terhadap Prestasi Kerja Karyawan Pada PT. Handaru Nusantara Gemilang (Dapoer Intan). JENIUS (Jurnal Ilmiah Manajemen Sumber Daya Manusia), 2(2), 244-259.

Sunarsi, D. (2019). Penerapan MSDM Strategis Dalam Upaya Meningkatkan Kemampuan Organisasi dalam menyongsong Revolusi 4.0. Jurnal Ilmiah MEA (Manajemen, Ekonomi, \& Akuntansi), 3(1), 221-233.

Suparyadi. Manajemen Sumber Daya Manusia, Penerbit : CV. Andi Offset, Yogyakarta, 2015

Suryani, N. L., \& Kristianti, L. S. (2020). Pengaruh Insentif Terhadap Kinerja Karyawan Pada PT. Trimegah Perkasa Di Jakarta. JENIUS (Jurnal Ilmiah Manajemen Sumber Daya Manusia), 4(1), 96-104.

Wahyudi Bambang, 2012, "Manajemen Sumber Daya Manusia". Sulita Bandung.

Wibowo. Manajemen Kinerja Edisi Kelima, Penerbit : PT. Raja Grafindo Persada, Jakarta, 2016

Zakiyudin, Ais. Sistem Informasi Manajemen. Penerbit: PT. Mitra Wacana Media, Jakarta, 2011. 